\title{
Attitudes of South African Dental Therapy Students Toward Compulsory Community Service
}

\author{
Ahmed Bhayat, M.Dent.; Veerasmay Yengopal, M.C.H.D.; Michael J. Rudolph, B.D.S., \\ M.Sc., M.P.H.; Urvashnee Govender, B.O.H.
}

Abstract: Compulsory community service (CCS) was introduced into the health service by the South African government to address the shortage and maldistribution of health professionals within the public sector. The aim of this study was to determine the attitudes of dental therapy students regarding CCS. A self-administered questionnaire was delivered to the two dental schools that train dental therapists in South Africa. There was a 64 percent response rate; 56 percent of the respondents were female. The average age was 20.3 years. There was no difference in the variables between the two dental schools, so the results were combined. The majority (81 percent) supported the introduction of CCS and preferred to carry it out in Kwa-Zulu Natal. Most students opted to perform oral health promotional (64 percent) and clinical (15 percent) activities. By aligning these requirements with the current dental needs and priority strategies of the South African Department of Health, this support would add much value to the delivery of oral health services.

Dr. Bhayat is Specialist in Community Dentistry, Division of Public Oral Health, Schools of Public Health and Oral Health Sciences; Dr. Yengopal is Specialist in Community Dentistry, Division of Public Oral Health, Schools of Public Health and Oral Health Sciences; Dr. Rudolph is Chief Specialist and Head, Department of Community Dentistry, Division of Public Oral Health, Schools of Public Health and Oral Health Sciences; and Ms. Govender is Oral Hygienist, Division of Public Oral Health—all at the University of the Witwatersrand. Direct correspondence and requests for reprints to Dr. Ahmed Bhayat, Schools of Public Health and Oral Health Sciences, University of the Witwatersrand, 10 ${ }^{\text {th }}$ Floor/Room 10Q20, 7 York Road, Parktown 2193, Johannesburg, South Africa; 011-717-2247 phone; 011-717-2625 fax; ahmed.bhayat@wits.ac.za.

Key words: dental therapy, compulsory community service, attitudes towards community service, dental education in South Africa

Submitted for publication 2/18/08; accepted 5/29/08

$\mathrm{T}$ There is a shortage of human resources to meet the oral health needs of communities in South Africa. ${ }^{1,2}$ The workload of the limited personnel has been expanded by the introduction in 1994 of free oral health services at public oral health facilities in primary health care settings. This policy has resulted in an increase in patient attendance although the number of personnel has remained fairly stable. ${ }^{3,4}$

The South African Department of Health $(\mathrm{DOH})$ has initiated various strategies to address the human resource shortage in public health, including the introduction of year-long compulsory community service (CCS) and rural allowances for scarce skills. ${ }^{5}$ None of these initiatives has yet been introduced for the oral health practitioners known as dental therapists. However, the $\mathrm{DOH}$ is planning to introduce a one-year CCS program for dental therapists in the near future. Managers in the oral health directorates as well as faculty in the dental schools in South Africa support the introduction of the CCS for dental therapists.
In December 1997, South Africa's Health Professions Amendment Act endorsed the concept of CCS for all health professionals. ${ }^{5}$ The aims of CCS are to improve the provision of health services to all citizens; improve the clinical skills of newly qualified health professionals; address the lack of doctors and dentists working in the public service rural hospitals; and increase the human resource capacity in the public sector.

Currently, two dental schools are accredited to train dental therapy students in South Africa: the University of Limpopo and the University of KwaZulu Natal, which are located in the Limpopo and Kwa-Zulu Natal provinces respectively (Figure 1). However, there are proposals for all dental schools in South Africa to train and increase the number of dental therapists that are graduating on an annual basis. ${ }^{6}$ The trend to train more dental therapists and fewer dentists is an initiative undertaken by most developing countries in an attempt to address the shortage of skilled oral health care workers. ${ }^{6,7} \mathrm{~A}$ review by Nash et al., ${ }^{7}$ taking the global perspective on 


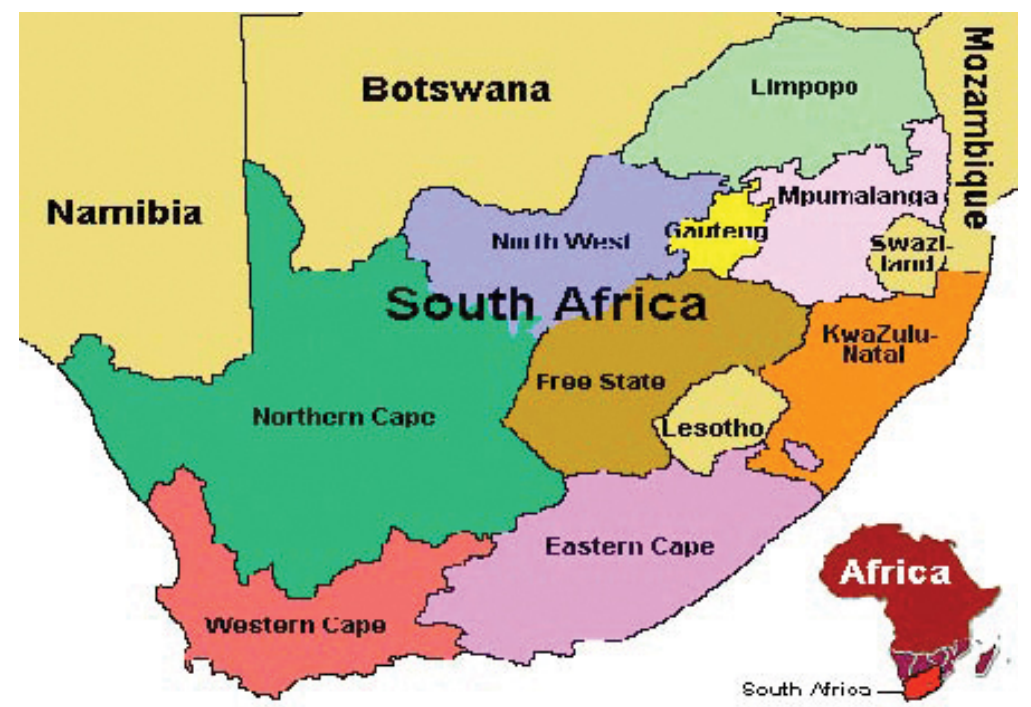

Figure 1. Map of South Africa

dental therapists, reported that developing countries such as New Zealand, Australia, and Tanzania train dental therapists to provide curative and preventive treatment within the public sector. However, in South Africa, similar to other developing countries, qualified dental therapists are eligible to practice either in the private or public sectors, and most of them are now opting for the private sector. ${ }^{7}$ The most common reasons for this choice are the financial rewards and the freedom to work in urban areas rather than the rural and remote areas for which the public sector has the greatest responsibility. This imbalance results in many dental therapists not fulfilling their initial primary objective - to provide services to the underprivileged and rural communities who do not have access to private dental services. By introducing $\mathrm{CCS}$, these newly qualified health workers would be compelled to serve at least one year within the public oral health facilities and, by so doing, render oral care to the vast majority of rural communities. This would increase the accessibility and affordability of oral health services to the poorest and most underserved communities. ${ }^{6}$

Dental therapists in South Africa, similar to those in other developing countries, are allowed to perform the following dental services: dental examinations, restorations, extractions, radiographs, taking of impressions, minimum intervention dentistry (MID), administration of local anaesthetics, and scaling and polishing. ${ }^{7}$ Given the wide range of clinical duties that dental therapists are permitted to perform, they would be able to treat and prevent the most prevalent oral health problems in South Africa, the most important of which is dental caries. ${ }^{1}$ If compelled to perform CCS, an annual cohort of dental therapists would most probably be placed into rural public oral health facilities to provide basic preventive and curative care for those communities.

The results of the 1999-2002 National Children's Oral Health Survey ${ }^{1}$ for South Africa indicated a huge unmet need for basic oral health care procedures such as restorations, extractions, and fissure sealants. A major concern arising from this data was the large amount of untreated caries in young children, varying between 45 percent and 60 percent of these children within the nine provinces.

Dentists alone cannot meet the current high unmet oral health needs of the population. ${ }^{2}$ The recommendations made by Van Wyk, ${ }^{1}$ which were also supported by Gordon, ${ }^{8}$ suggested that most of the oral health problems in South Africa could be prevented and treatment carried out by dental therapists and/or oral hygienists. Gordon analyzed the oral disease profile in South Africa and concluded that the majority of patients who seek dental treatment require dental extractions and basic restorations, which could be treated by dental therapists. She further suggested that most oral conditions could be prevented if ad- 
equate preventive programs were in place. However, for a number of reasons including a lack of human resources, these preventive programs have not yet been effectively implemented.

If dental therapists are compelled to perform CCS, they would increase the staff complement and could supplement and enhance prevention programs that are desperately needed within the communities. Dental therapists could also play a vital role in the treatment of dental conditions by carrying out minimal intervention dentistry, simple restorations, and extractions. ${ }^{9}$ No study in South Africa has evaluated the views and opinions of dental therapy students regarding the introduction of CCS. The objectives of this study were therefore to obtain demographic data on the dental therapy students registered in 2004, assess their attitudes towards the introduction of CCS, and determine the types of activities they would like to perform.

\section{Methods}

This was a cross-sectional descriptive study, and all data were collected by means of a self-administered questionnaire. Two dental schools, the universities of Kwa-Zulu Natal and Limpopo (MEDUNSA campus), currently offer dental therapy training; both were included in this study. The study population consisted of all dental therapy (DT) students who were registered during 2004 at these two dental schools. There were sixty-five and twenty students registered at the universities of Kwa-Zulu Natal (UKZN) and Limpopo (UL), respectively. The survey instrument consisted of seventeen closed and two open-ended questions eliciting information regarding the stu- dents' sociodemographic profile, their perceptions and attitudes regarding CCS, and the types of clinical activities/services they would like to carry out whilst performing CCS.

The data were analyzed by means of descriptive statistics together with bivariate analysis using Epi Info version 3.2.2. The data from the two openended questions were grouped using basic qualitative data research methods and reported separately. The Mantel-Haenszel chi-square test and correlation coefficient analysis $\left(\mathrm{r}^{2}\right)$ were used to determine the association between variables, and the confidence levels were set at 95 percent.

\section{Results}

A total of eighty-five DT students were registered in 2004, and fifty-four (64 percent) responded to the questionnaire. The response rates from the UKZN and UL were 69 percent $(\mathrm{N}=45)$ and 45 percent $(\mathrm{N}=9)$, respectively. The results from the two dental schools were pooled as there was no significant difference (in terms of age, gender, and race) between the groups. Of those who responded, twenty-four (44 percent) were male, and thirty ( 56 percent) were female. The average age was 20.3 years (range $=17-29$ years; std. dev. 2.6), with the majority ( 89 percent) between seventeen and twenty-three years old. Almost threequarters ( 74 percent) of all respondents resided in the Kwa-Zulu Natal province. The racial breakdown of the students is shown in Figure 2. (Note that, prior to 1994, all people in South Africa were classified African, Indian, Coloured, or White according to the Population Registration Act of 1950. The use of these terms does not support the legitimacy of this

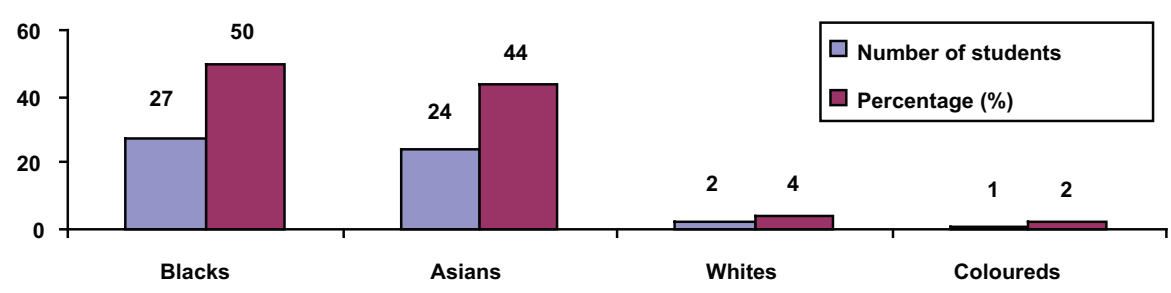

Figure 2. Racial distribution of students $(\mathrm{N}=54)$ 
racist terminology, but is necessary for highlighting the impact of former apartheid policies on people in this country.) Half the respondents were black, and more than 40 percent were Asian.

In responses to the survey, the majority of DT students ( $\mathrm{N}=43 ; 81$ percent) supported the concept of CCS (Table 1). The positive responses from the two dental schools were similar $[78$ percent $(\mathrm{N}=7)$ and 82 percent $(\mathrm{N}=36)]$. There was no statistically significant difference between the two schools in their students' race $(p=0.6)$, age $(p=0.1)$, gender $(p=0.08)$, or university $(p=0.5)$ and their willingness to perform CCS. Hence, all subjects were pooled for further analysis.

Those students who responded positively towards the introduction of CCS listed various reasons as shown in Table 2. These data were obtained from the open-ended question; also, some students provided more than one reason for their support of this response. Of the students who felt that CCS should not be introduced, their main reasons included poor salary packages and a health care system that was poorly organized (Table 3 ). Some of the students listed more than one reason, so there were more than ten responses.

Almost two-thirds ( $\mathrm{N}=35 ; 64$ percent) of the respondents chose the Kwa-Zulu Natal province as their first choice for placement. This was not unexpected as the majority of respondents resided in that province. A small number of students chose the North West (11 percent) and Gauteng (9 percent) provinces. A significant number ( 81 percent) of students wanted to perform CCS in their resident province $\left(\chi^{2}=143.33 ; p=0.001\right)$.

The respondents indicated that they would prefer to carry out oral health promotional activities (64 percent) and clinical work (15 percent). Only a few students indicated research ( 2 percent) and management ( 2 percent) as areas of interest.

\section{Discussion}

The response rate (64 percent) was lower than expected, given the captive target audience and the importance of this topic. However, some of the senior students from UL were on a two-week study break, which could have resulted in the lowered response rate obtained from that dental school.

The number of respondents who chose their province of residence to perform CCS was statistically significant $(p=0.001)$. However, it must be borne in mind that more than half of the currently placed CCS dental students are not placed in their residential

Table 1. Responses about the introduction of CCS by dental school

\begin{tabular}{lcrr} 
& In Favor of CCS (\%) & Against CCS (\%) & Total Respondents \\
\hline University of Limpopo & $7(78 \%)$ & $2(22 \%)$ & 9 \\
University of Kwa-Zulu Natal & $36(82 \%)$ & $8(18 \%)$ & 44 \\
Total & $43(81 \%)$ & $10(19 \%)$ & 53 \\
\hline
\end{tabular}

Table 2. Reasons for wanting CCS to be introduced

Reason Number of Respondents

Improve clinical skills and gain experience and confidence 25

Help disadvantaged communities by providing basic oral health services 18

Provide employment opportunities

Learn more about the country and people's cultures and beliefs

2

1

Table 3. Reasons for not wanting CCS to be introduced

Reason

Number of Respondents

Poor salary packages

Health resources were inadequate and the health care system was poorly organized

Prefer to work in the private sector

Personal commitments and family reasons 
province but in rural and remote areas. This placement process depends on the availability of human and financial resources and the needs of the various communities within South Africa. Thus, the placement of students in communities away from their residential provinces has been shown to be of concern for some medical students ${ }^{10}$ and can be expected, in turn, to be of equal concern for the dental therapists. This process may lead to dissatisfaction amongst these therapists and perhaps result in problems with service delivery and morale. ${ }^{10}$

However, Naidoo and Chikte ${ }^{11}$ documented the experiences of dentists who had completed their CCS and did not identify problems in the placement of students in provinces other than their resident province. This result was confirmed by Azer et al., ${ }^{12}$ who reported on Australian medical students who were placed into rural and underserved communities.

Naidoo and Chikte ${ }^{11}$ did, however, report that students were dissatisfied with the placement process in general and wanted the process to be more transparent. These authors suggested that future CCS placement of students should be a fair and open process. They further advised that when placing students into CCS posts, health managers must be aware of the health resources at the different accredited placement sites and have the necessary information regarding the health needs of those communities. This would ensure that all stakeholders - namely, the students, communities, and staff at the health facilities - benefit from the CCS program.

More than eighty percent ( 81 percent) of DT students supported the introduction of CCS, but only 15 percent felt that CCS would be a means of enhancing their confidence and clinical skills. Other studies $^{10-12}$ done on health workers who completed their CCS reported an improvement in their confidence and clinical skills. This difference could be attributed to the fact that DT students may not fully appreciate the advantages of working outside their dental schools and within community settings. It is also possible that these students have not been exposed to different environments and settings outside their school. Hence, they may not be fully aware of the needs and types of patients that are found in different communities. Once they start working, they may identify their own shortcomings and weaknesses and improve on these.

A large number of respondents (81 percent) were of the opinion that, by performing CCS, they would positively contribute to improving the oral health knowledge and practices of disadvantaged and rural communities. This positive outcome confirmed the results obtained from Naidoo and Chikte ${ }^{11}$ and Azer et al. ${ }^{12}$ The provision of oral health services to disadvantaged and rural communities can be a rewarding experience, and the introduction of CCS could thereby impact on the young dental therapists' growth and personal development.

This apparently positive response for the introduction of CCS may have been biased. The respondents in this study were well aware that they themselves would not be doing CCS, which may have resulted in students responding in an affirmative manner due to the Hawthorne effect. ${ }^{13}$ The students were aware that CCS would benefit poor and deprived communities, which would also motivate them to respond positively.

The majority of students who were in disagreement with the introduction of CCS for their profession cited poor salary packages and financial reimbursement. Some students suggested that the health sector was not ready to place dental therapy graduates in CCS posts. This argument is valid since many dentists were placed in posts that did not have sufficient resources, staff, and management structures. ${ }^{11}$ Of greater concern to the Department of Health ${ }^{10}$ is the current routine placement of CCS dentists in urban settings. One of the aims of CCS is to address the maldistribution of health workers by placing students in rural and deprived areas, so that these disadvantaged communities have access to basic health care services. However, due to a lack of resources and inadequate management and supervision in rural areas, the DOH has no option but to place the CCS dentists in urbanized areas. Nonetheless, the demand for oral health services is equally great in urban and semi-urban areas, and staff working in these areas are unable to cope with the demand. Hence, although dentists are placed in the urban areas, they still play an essential part of the service delivery and help meet the dental needs of the communities in which they are placed. The introduction and placement of newly qualified dental therapists would require further investment and commitment from the nine provinces to ensure that they are optimally utilized for service delivery.

The introduction of CCS for these oral health professionals would provide an additional and valuable human resource in South Africa, where there are severe shortages of trained oral health practitioners. ${ }^{1,14}$ In addition to meeting the basic oral health needs, they could play a role in the diagnosis and treatment of oral lesions associated with HIV/AIDS 
and refer suspected HIV-positive patients for voluntary counselling and testing, a critical component of the government's HIV care and prevention strategy.

Holtshousen ${ }^{15}$ found that more than 80 percent of dentists who had completed their CCS in the Gauteng province of South Africa in 2003 had done mainly extractions. These young practitioners were of the opinion that their skills were not being fully utilized and that they had lost some of their clinical capabilities, e.g., in fixed prosthodontics. If CCS for dental therapists is introduced, extractions and most preventive dental procedures could be done by them, allowing the dentists to carry out more specialized dental procedures. This would, however, require an upgrading of current dental facilities in the public sector in order to cope with the increased staff complement.

The implementation of CCS for dental therapists could ease the workload of the oral health staff currently employed within the public sector. Furthermore, the added human resources may facilitate an improvement in the execution and sustainability of prevention programs, which in turn could reduce the high caries and periodontal disease levels in South Africa. ${ }^{1}$ The dental therapy students prioritized health promotion (64 percent) as an activity they would like to carry out during their CCS. Health promotion is one of the five pillars of the primary health care (PHC) approach and a strategy committed to the prevention of oral diseases by providing adequate, practical, and relevant knowledge. ${ }^{16}$ The lack of effective oral health education and promotion in both rural and urban areas is well known. ${ }^{17,18}$ It is possible that dental therapists could implement and manage such programs on a more consistent basis. One of the aims of the National Oral Health Strategy ${ }^{19}$ is the provision of preventive services such as oral health promotion, prevention, and placement of fissure sealants; dental therapists could be the drivers of these programs.

Only a small percentage ( 15 percent) of the respondents chose clinical work as an option, suggesting that the majority of students ( 85 percent) felt that they were adequately trained and qualified to perform clinical functions. Most of them expressed the view that they would like to do health promotional activities (school- and crèche-based oral screenings and the provision of oral hygiene instructions at health clinics, hospitals, and schools), which is in contrast to studies done with newly qualified dentists and doctors. ${ }^{12,20,21} \mathrm{~A}$ possible reason for this difference is the strong emphasis placed on prevention and health promotion at the training institutions compared to the medical/dental curriculum, which focuses mainly on clinical skills.

\section{Conclusion}

This study sought opinions from amongst a cadre of health workers who have not been exposed to CCS. These views could assist the Department of Health in better planning the introduction of CCS for dental therapy and other health professionals. By aligning the potential services of the dental therapists with the dental needs of the wider communities, the $\mathrm{DOH}$ would have a win-win situation. The communities would receive basic oral health care, while the young graduates would make a huge contribution in providing these services and simultaneously improving their skills. CCS could also be a model for other countries that wish to improve the provision of health services to all citizens, improve the clinical skills of newly qualified health professionals, address the inadequate number of dentists working in public service rural hospitals, and increase the human resource capacity in the public sector.

\section{REFERENCES}

1. Van Wyk PJ. Caries status and treatment needs in South Africa: report of the 1999-2002 national children's oral health survey. S Afr Dent J 2004;59:238-42.

2. National oral health survey, South Africa 1988/89. Compiled by PJ van Wyk. Pretoria: Department of Health, 1994.

3. Harkinson BN, Cleaton-Jones PE. Attendance rates in Soweto dental clinics, 1995-2003. S Afr Dent J 2004;59(4):147-9

4. Bhayat A, Cleaton-Jones P. Dental clinic attendance in Soweto, South Africa, before and after the introduction of free primary dental health services. Community Dent Oral Epidemiol 2003;31:105-10.

5. Department of Health. White paper for the transformation of the health system in South Africa. Government Gazette. Pretoria: Government Printers, 1996.

6. Lalloo R. A national human resources plan for oral health: is it feasible? S Afr Dent J 2007;62:360-4.

7. Nash DA, Friedman JW, Kardos TB, Kardos RL, Schwarz E, Satur J, et al. Dental therapists: a global perspective. Int Dent J 2008;58:61-70.

8. Gordon NA. A national survey of oral hygienists in South Africa. S Afr Dent J 2004;59(5):184-8.

9. Mickenautsch S, Rudolph MJ. Implementation of the ART approach in South Africa: an activity report. S Afr Dent J 2001;56(7):327-9.

10. Reid S, Conco D, Varkey SJ, Fonn S. Implementation of legislation: community service for doctors. In: Crisp N, 
ed. South African health review. Durban: Health Systems Trust, 1999:chapters 17 and 26.

11. Naidoo S, Chikte U. Community dental service: the first year. S Afr Dent J 2002;57(5):193-6.

12. Azer SA, Simmons D, Elliott SL. Rural training and the state of rural health services: effect of rural background on the perception and attitude of first-year medical students at the University of Melbourne. Aust J Rural Health 2001;9:178-85.

13. Adair G. The Hawthorne effect: a reconsideration of the methodological artifact. J Appl Psychol 1984;69(2): 334-45.

14. Strachan K. What the Department of Health says. HST Update 2000;57:8.

15. Holtshousen WSJ. Service rendering statistics of compulsory community service dentists in Gauteng. Presentation at the 2004 Meeting of the South African chapter of the International Association for Dental Research, in Pretoria.
16. Jacob MC, Plamping D. The practice of primary dental care. Cambridge, Great Britain: Wright, 1989:63-7.

17. Hassam S, Munsamy C, Laher T, Bawa T, Mahomed N, Ismail N. An evaluation of the effectiveness of oral hygiene programmes in schools in Soweto. Unpublished report, 2004.

18. Maraj E, Kroon J. Impact of school dental service on periodontal health and oral hygiene. Presentation at the 2003 Meeting of the South African chapter of the International Association for Dental Research, in Cape Town.

19. National oral health strategy. Pretoria: National Oral Health Directorate, 2005.

20. D'Cruz L. A survey of the views of vocational dental practitioners on continuing professional education. Prim Dent Care 1998;5(3):121-4.

21. Reid SJ. Crisis in rural South Africa. S Afr Fam Practitioners 2001;23:17-8. 